\title{
Digital Child Pornography: Reflections on the Need for a Critical IS Research Agenda
}

\author{
Marie Eneman \\ Informatics, University of Göteborg, Sweden. \\ eneman@informatik.gu.se
}

\begin{abstract}
The purpose of this paper is to argue for the need for systematic empirical information systems research within the field of digital child pornography. This research area is today primarily driven by non-technical disciplines. This paper argues that without the IS perspective an adequate understanding of the role of ICT, its use and effects for child pornography cannot be obtained. The IS perspective is an important complement to the existing body of research attempting to understand the area of digital child pornography. The paper is based on the argument that the research area of digital child pornography is well suited to the application of critical information systems research.
\end{abstract}

Keywords: digital child pornography, IS perspective, critical information systems research

\section{Introduction}

The introduction of information and communication technologies (ICT) in everyday usage has greatly increased the problem of child pornography [1,2]. Child pornography is an emotive topic, where public discourses tend to be dominated by subjective opinions and moral positions rather than rationale debates based on empirical findings [3].

Research disciplines such as law $[4,5,6,7]$ and psychology $[8,9,10]$ have been early to explore the connection between ICT and child pornography. In comparison, the information systems (IS) discipline has been slow to recognise the key role it has to play in the study of child pornography [1]. The purpose of this paper is to argue for the need for systematic empirically based IS research within the field of digital child pornography. The focus of IS research is ICT, its use and effects $[11,12]$ while the focus of other disciplines is to respond to their own questions. Therefore, the

Please use the following format when citing this chapter:

Eneman, M., 2006, in IFIP International Federation for Information Processing, Volume 223, Social Informatics: An Information Society for All? In Remembrance of Rob Kling, eds. Berleur, J., Numinen, M. I., Impagliazzo, J., (Boston: Springer), pp. 111-121. 
results of a legal study on child pornography and ICT will provide valuable insights into the legal situation but will not provide an adequate understanding of the technology effects involved since the non-technical disciplines lack a technical focus and competence. This paper will show that the study of the use of ICT outside the traditional scope of organisations is an important field of endeavour and lies within the field of expertise of the IS discipline. Furthermore this paper argues that digital child pornography is a suitable area in which to apply critical information systems research (CISR).

This paper begins with an overview of CISR. This will be followed by a section, which places child pornography in a wider context, and thereafter follows a section on the effects of ICT on child pornography. This is followed by a section where CISR is applied to the research area. In conclusion the author reviews this paper's contribution to the CISR and digital child pornography research fields.

\section{Critical Information Systems Research}

Within IS research the discussion on the widespread dissemination of ICT in society has mainly focused upon the benefits involved in ICT usage [13, 14]. This simplified approach tends to omit the fact that the technology is not one-sided and that the dissemination of any technology brings with it both pros and cons [15]. This paper will give examples of how well established uses of ICT are being used for harmful purposes, such as digital child pornography. This follows Wajcman's [13] argument that despite efforts to inscribe users and uses in technology design we cannot predict the future uses of the technology.

CISR can be seen as a reaction to the mainstream IS research which tends to assume that technological innovation is 'inherently desirable' and beneficial to all [16]. In the field of IS, the call to engage in critical research has been explicitly voiced by a growing numbers of researchers $[14,17,18,19,20,21,22,23,24,25$ $26,27]$. The adoption of CISR can also be understood as a rejection of the understanding of technology development within society as being based on solely economic terms $[14,27]$.

CISR encompasses a wide range of different research subjects, objectives, methods and philosophical starting points. However, these disparate applications of CISR all share a common denominator in their critical perspective [14, 28]. One example of a research agenda within CISR is Social informatics (SI). SI is the study of the social aspects of computers, telecommunications and related technologies [29, $30,31,32]$. One of the key issues with SI is that it takes the study of ICT beyond organisational boundaries and therefore is able to ensure that IS plays an active part in the study of social phenomena connected with technology, such as digital child pornography [29].

Engaging in CISR entails the study of the research object with the aid of concepts relevant to critical theory, for example domination, power and control, emancipation empowerment etc [28]. In addition to using the relevant concepts the research object should be placed in a wider historical, political, social and economic context [33]. According to Alvesson and Deetz [33] three central elements should be 
included when conducting critical research, (insight, critique and transformative redefinition).

Insight is the process where the research area is investigated and interpreted. This process includes: how the data should be collected, the collection process, and the interpretation. Insight is achieved by questioning and challenging established assumptions and definitions and by interpreting the non-obvious aspects of the studied phenomenon. The following process (critique) involves the critical analysis of the insights obtained in the previous stage and relates this analysis to wider social and historical processes. The last process (transformative re-definition) is the natural complement to insight and critique. It is, however, the most difficult part of the three elements. The goal is to develop critical knowledge, practical understanding and to offer alternatives to the established dominant assumptions and definitions. The purpose of this developed knowledge is to enable change and through this to contribute to a process of emancipation.

Therefore critical IS researchers are not primarily concerned with the efficiency of technology, but with questioning and challenging established assumptions and definitions regarding the technology, its use and effects in society [14]. The purpose with this approach is to move beyond established assumptions, which dominate the public discourses [34]. Kling et al [34] argue that the public discourses on technology are often both one-sided and simplified 'disconnected discussions'. This disconnected discussion is well represented by the debate of digital child pornography presented by the media. It is often one-sided, inadequate and often lacking in empirical basis [35, 36].

These types of public disconnected discourses create a hinder if the goal is to establish positive social change in relation to ICT use. One way in which such discourses act as hindrances is that they create oversimplified conceptual models [34] of the role of ICT in society. In order to go beyond vague generalisations it is important to be more specific and define what is meant with the term ICT [37]. Orlikowski and lacono [12] argue that the focus should be on the IT artefact and Walsham [27] argues that the area of use should be presented. Despite the common terminological misuse, ICT is not one homogenous technology. It consists of several different technologies, which have different characteristics, and there are also variations in how different technologies are interpreted and used [11].

One of the difficulties with engaging in critical IS research is that the guidelines for how to conduct critical IS research are scarce and sketchy. Critical IS researchers have focused on defining what it means to be critical, but largely ignored to explicitly define how criticality can be achieved in IS research [16]. McGrath [16] argues that CISR has not yet reached a position where theory and practice of critical research inform each other. CISR, as a field, would benefit if its researchers become more explicit in their approach, especially when carrying out empirical studies.

This paper is part of a larger ongoing research project regarding digital child pornography, where empirical studies are conducted in line with the CISR agenda. One of the difficulties with researching the area of digital child pornography relates to methodology. This is due to the fact that many actions surrounding the phenomenon constitute criminal offences and are, at the same time, considered highly unacceptable in society. Examples of empirical material used within this project are: Swedish court findings concerning child pornography during the period 
of 1993-2003, Swedish criminal investigation records and in-depth interviews with convicted offenders. The importance of using empirically based data in studying social consequences of ICT has been pointed out by Kling [30].

\section{Contextualising Child Pornography}

The central idea in critical research is that all social phenomena are historically created and conditioned [38, 39, 40]. Therefore the research object, digital child pornography, will here be placed in a wider historical, political, social and economic context of the research field $[41,42]$.

Child pornography is not a new phenomenon. Historically, the dissemination and consumption of child pornography was achieved through costly magazines, photographs and videos and therefore child pornography was limited by economic, physical and logistical boundaries [43]. Child pornography has been produced in different forms, using whatever technological media was available at the time [8]. Similar patterns can be seen in the technical developments within the pornography industry. Technological developments and pornography are deeply interconnected with pornography driving technological advancements and new technologies affecting pornography content $[44,45]$. The economic context of digital child pornography has not been adequately studied but there is evidence of a growing commercialisation in this area [46].

The term digital child pornography refers to child pornography where ICT has been used as a medium in some form. While legal definitions of child pornography can differ greatly between jurisdictions, it is possible to discern a generally accepted definition of the term. One such generally accepted definition is: representations where a child is engaged, or appears to be engaged, in some kind of sexual act or situation [10]. The content can vary from posing pictures [8] to physical sexual abuse of children [47].

There is some debate as to the adequacy of the term child pornography. Some researchers $[47,48,8]$ argue that the term child pornography is unfortunate and misleading as it reduces the gravity of what the material portrays and invites comparisons with adult pornography. Gillespie [48] argues for the use of the terms 'indecent' or 'abusive' images since these terms better describe the material. Notwithstanding this terminological debate, research $[1,8,49]$ shows that there is an obvious connection between pornography and child pornography. This connection constitutes an important argument that these phenomena should not be studied as isolated research areas. Child pornography should be placed in the wider pornography context $[1,43]$. However, there are obvious and important differences between the two due to the clear asymmetrical power relationship $[1,50]$ between the adult and the child.

When discussing pornography and/or child pornography one should be aware of the longer ongoing debate concerning pornography versus issues as freedom of expression and censorship [51, 52]. An example of this debate can be found in the Swedish debate, which took place in the beginning of 1990 s and concerned the criminalization of the possession of child pornography. This debate was dominated 
on the rights of the child versus the limitations on constitutional rights of freedom of expression. The possession of child pornography was criminalized in 1999 in Sweden. The current Swedish legal position criminalises the production, distribution and possession of child pornography (Swedish legislation has proven to be inadequate in parts [e.g. 48, 2]).

\section{Digital Child Pornography}

Child pornography has changed radically since the mid-1990s [46]. The underlying reasons for this change can be explained partly by the effects of the dissemination of ICT and partly by the effects of changes in child pornography laws [2]. This section will illustrate how ICT is being used for child pornography. Following activities will be used as examples: production, distribution, consumption, networking and grooming.

First ICT simplifies the production of child pornography and enables it to be conducted at low cost [8]. By using digital technology, images and films can easily and quickly be produced and stored. The development of ICT has enabled nontechnically skilled users to record, store and manipulate images in a way which was previously only available to people with the requisite technical skills and costly equipment [43]. Therefore, today even non-technically skilled users can record their abuse of children and thereafter easily distribute the material through ICT. Secondly ICT offers software tools, which can easily be used to produce so-called morphed images, also called pseudo-photographs. Morphing images entails the use of digital graphics software, to combine two images into one, or to distort pictures [4]. This means that non-pornographic images of real children can be made to appear as child pornography, and child pornographic images of 'virtual' children can be generated [53].

Similarly ICT have affected the volume of material which it is now possible to distribute and consume across networks [1]. The technology offers features to manage large amounts of data easily, rapidly, at low cost and is readily available without a high level of technical knowledge [43].

Computer networks also allow paedophiles to create online communities [54]. The communities function as places where paedophiles share and trade information and material. These communities allow them to meet other paedophiles. Together in the community they can legitimise their interests and establish important contacts. The importance of the legitimising effect can be explained by the fact that it is important for paedophiles to feel that their sexual interests for children are accepted by people around them, and that they feel they obtain social status and support within these environments $[8,55]$.

Further, ICT have created new ways and conditions for people to establish contacts and to interact with other people [56], including children. A development, which has come in the wake of online communication, is the problem of grooming [7]. Grooming refers to the activity when an adult initiates and establish contacts with a child online with the intention of preparing the child for later physical meeting [57] or with the intention to communicate with the child online to attain sexual 
gratification (with no intention of arranging physical meetings) [58]. ICT offers features for users to portray themselves to better fit their purpose [59] and, of course, they can retain their anonymity by using pseudonyms. The ability to contact children through ICT also increases the number of children available compared to real life, where geographical limitations and social exposure decrease this availability [7]. Another aspect that facilitates paedophiles in contacting, communicating and interacting with children through ICT is the lack of parental knowledge. Parents often do not know what their children are actually doing when spending time online [60].

\section{Digital Child Pornography and CISR}

The approach taken in this work follows the eloquent motivation posited by Walsham [61]: "To simplify, a critical stance is focused on what is wrong with the world rather than what is right. It tends to focus on issues such as asymmetries of power, alienation, disadvantaged groups or structural inequity." The role of the critical researcher within this study is to, through research, lay the foundations for a more open, well founded societal debate on digital child pornography. This is best achieved by providing alternatives to the dominant understanding within society. [33]. In this section the paper will discuss the three elements of critical research (insight, critique, transformative re-definition) [33] in relation to digital child pornography.

\section{Insight}

This stage concerns itself with the collection and interpretation of data. The goal is to bring about a questioning of established assumptions of digital child pornography. In the previous section certain digital child pornography activities were highlighted with the intention to show how technology is being used.

The identified activities exemplified above (production, distribution, consumption, networking and grooming) have emerged from the empirical data [8, 2]. By studying these activities, through the interpretation of the empirical data, the following insights have been reached. They are based upon a technological focus i.e. the empirical data is studied to increase our understanding of the use of technology (which activities and which ICT has been used). By employing this focus the researcher avoids the practices of black-boxing technology [37] or viewing technology as a neutral, autonomous tool [62].

Among the insights identified in this paper are: child pornography is a serious social problem, which has been made worse with the advent of digital technology. Despite the important role of technology within this area the IS discipline has been slow to recognise this as an important research area. Research within this area has been driven by non-technical disciplines (e.g. law, psychology). The public discourse on this topic is seldom based in adequate empirical research. One of the difficulties within this field is the access to empirical data since the acts are criminalised in most western countries and often viewed as socially unacceptable. 


\section{Critique}

The next stage is the critique of the insights by placing them in a wider context [41]. Prior to this it is important to reflect upon the empirical sources, which are the basis of the insights [14]. When studying digital child pornography one of the sources of material is to be found in court findings and criminal investigation records. It is important to be critically aware of the consequences of the choices of using this material [33]. This material is produced in a specific context and for a specific purpose. The consequences of this are that the role of technology is not the focus of the material, which means that the researcher must attempt to understand what is not obvious in the material [33]. To counteract the bias of the material interviews with convicted paedophiles can be carried out. Even in this case the researcher must be aware that the topic of the interview is a sensitive subject. Despite these limitations in the empirical data the material provides a rich source of information about the use of technology in the child pornography context.

Alvesson and Skoldberg [63] argue that there is a natural tendency to interpret existing social reality from a taken-for-granted perspective and that this approach must be counteracted. One approach to developing a dialectic understanding of technology is by problematizing the effects of ICT [41]. The use of ICT as a medium for child pornography should not simply be seen as an additional channel of communication: the harnessing of digital technologies in relation to child pornography has changed the traditional problem, creating a new, more serious, situation [44]. This paper adopts the perspective that ICT is not a neutral tool [62] and that it poses qualitative changes to child pornography [2].

This paper has shown that allowing the non-technical research disciplines to drive this field is an inadequate approach in developing a well-rounded understanding of digital child pornography. This is because other disciplines have their own research agendas, just as the IS discipline has it own. The important difference here is that within the IS discipline the technology, its use and effects [12] are in focus, which is not the case for non-technical disciplines.

Digital child pornography is a phenomenon influenced by different rationales (e.g. technological, power, emotion) $[40,50]$ and these rationalities are constructed and shaped within wider contexts. The emotional rationale [50] is well represented in the public discourse on digital child pornography as it is particularly emotional and tends to rely more on morality and subjective opinion than empirical findings. In addition to the public discourses being inadequate as a base for further development and social change they may also act as an obstacle to the development of a more well-founded discussion [3].

\section{Transformative Re-definition}

The goal of the transformative re-definition is to build upon insight and critique to provide alternative understanding of the research area [33]. The goal is to develop knowledge with an aim to enable change and emancipation [28]. To enable change within this area a well founded understanding of the technology involved is essential. Without such an understanding it is not possible to present credible alternatives to 
those presented by other research areas or accepted in the one-sided media discourse. By providing a realistic understanding of the effects of technology the social change can be enacted through law, policy or social practice. A brief example can be seen in the discussion on the application of filtering technology to prevent child pornography. While these technologies have received popular acceptance in the media they are based on a lack of understanding of the diversity of ICT used for digital child pornography [55].

\section{Conclusion}

This paper has argued for the need for systematic empirically based IS research within the field of digital child pornography. This is important since it acts as an important complement to existing non-technical research within the area. The significant role played by ICT in child pornography demands the contribution of IS research to understand the complexity of child pornography. It is not adequate that non-technical disciplines such as law and psychology attempt to lead research within this area since these disciplines are not primarily concerned with the technological orientation.

Despite the fact that the presented area is onerous to study, systematic research must be carried out. This paper has shown that digital child pornography can benefit from being the subject of CISR since this perspective attempts to also study the negative effects of ICT in society by looking at aspects such as e.g. structural inequalities and disadvantaged groups. It is important to take the step from speculative theories and uninformed public discourses to well-founded empirical research. To be able to conduct critical research with the ultimate goal of social change, the IS discipline must be prepared to take social responsibility and participate in a larger social discourse beyond organizational boundaries.

\section{References}

1. A. Adam, Gender Ethics and Information Technology (Palgrave Macmillan, New York, 2005).

2. M. Eneman, The New Face of Child Pornography, in: Human Rights in the Digital Age, edited by M. Klang and A. Murray (Cavendish Publishing, London, 2005).

3. R. Kling, H. Rosenbaum, and S. Sawyer, Understanding and Communicating Social Informatics: A Framework for Studying and Teaching the Human Contexts of Information and Communication Technologies, (Information Today, Inc, New Jersey, 2005).

4. A. Gillespie, Child Pornography: Balancing Substantive and Evidential Law to Safeguard Children Effectively from Abuse, The International Journal of Evidence \& Proof, 9, 1-21, (2005).

5. K. Williams, Child Pornography Law: Does it protect children? Journal of Social Welfare and Family Law, 26(3), 245-261, (2004).

6. Y. Akdeniz, Controlling illegal and harmful content on the Internet, in: Crime and the Internet, edited by D. Wall (Routledge, London, 2001). 
7. S. Ost, Getting to Grips with Sexual Grooming? Journal of Social Welfare and Family Law, 26(2), 147-159, (2004).

8. M. Taylor and E. Quayle, Child Pornography: An Internet Crime, (Brunner-Routledge, Hove, 2003).

9. G. Holland, Identifying Victims of Child Abuse Images: An Analysis of Successful Identifications, in: Viewing Child Pornography on the Internet, edited by E. Quayle and M. Taylor (Russell House Publishing, 2005).

10. J. Wolak, D. Finkelhor and K. Mitchell, The Varieties of Child Pornography Production, in: Viewing Child Pornography on the Internet, edited by E. Quayle and M. Taylor (Russell House Publishing, 2005).

11. G. Walsham, Making a World of Difference: IT in a Global Context (John Wiley \& Sons Ltd., Chichester, 2004).

12. W. Orlikowski and C. Iacono, Research Commentary: Desperately Seeking the 'IT' in IT Research - A Call to Theorizing the IT Artifact, Information Systems Research. 12(2) 121-134 (2001).

13. J. Wajcman, Feminism confronts technology (Polity Press, Cambridge, 1991).

14. D. Howcroft and E. Trauth (eds), Handbook of Critical Information Systems Research (Edward Elgar, Cheltenham, 2005).

15. J. Thompson, The Media and Modernity - A Social Theory of the Media (Polity Press, Cambridge, 1995).

16. K. McGrath, Doing critical research in information systems: a case of theory and practice not informing each other, Information Systems Journal 15, 85-101 (2005).

17. K. Lyytinen and H. Klein, The critical theory of Jürgen Habermas as a basis for a theory of information systems, in: Research Methods in Information Systems, edited by E. Mumford, R. Hirschheim, G. Fitzgerald and A. Wood-Harper (North-Holland Publishing, Amsterdam 1985).

18. R. Hirschheim and H. Klein, Four paradigms of information systems development, Communications of the ACM, 32(10), 199-216 (1989).

19. R. Hirschheim and H. Klein, Realizing emancipatory principles in information systems research: the case for ETHICS, MIS Quarterly, 18(1), 83-109 (1994).

20. S. Jonsson, Action Research, in: Information Systems Research: Contemporary Approaches and Emergent Traditions, edited by H. Niessen, H. Klein and R. Hirschheim (North-Holland Publishing, Amsterdam, 1991).

21. O. Ngwenyama, The critical social theory approach to information systems: problems and challenges, in: Information Systems Research: Contemporary Approaches and Emergent Traditions, edited by H. Niessen, H. Klein and R. Hirschheim (North-Holland Publishing, Amsterdam, 1991).

22. K. Lyytinen, Information systems and critical theory, in: Critical Management Studies, edited by M. Alvesson and H. Willmott (Sage, London, 1992).

23. M. Myers and L. Young, Hidden Agendas, Power and Managerial Assumptions in Information Systems Development: An Ethnographic Study, Information Technology and People, 10(3), 224-240, (1997).

24. F. Wilson, The truth is out there: the search for emancipatory principles in information systems design, Information Technology and People, 10(3), 187-204 (1997).

25. K. Saravanamuthu, K. and T. Wood-Harper, Developing Emancipatory Information Systems in: (Re-)Defining Critical Research in Information Systems - An International Workshop, edited by A. Adam, D. Howcroft, H. Richardson and B. Robinson, (The University of Salford, 2001).

26. B. Doolin and A. Lowe, To reveal is to critique: actor network theory and critical information systems research, Journal of Information Technology, 17, 69-78 (2002). 
27. G. Walsham, Learning about being critical, Information Systems Journal, 15, 111-117 (2005).

28. D. Cecez-Kecmanovic, Basic assumptions of the critical research perspectives in information systems, in: Handbook of Critical Information Systems Research, edited by D. Howcroft and E. Trauth (Edward Elgar, Cheltenham, 2005).

29. R. Kling, What is Social Informatics and Why Does it Matter?, D-Lib Magazine, 5(1) (1999).

30. R. Kling, Social Informatics, in: The Encyclopaedia of LIS, (Kluwer Publishing, Amsterdam, 2001).

31. R. Lamb and S. Sawyer, On extending social informatics from a rich legacy of networks and conceptual resources, Information Technology and People, 18(1), 9-20 (2005).

32. S. Sawyer and H. Rosenbaum, Social Informatics in the Information Sciences: Current Activities and Emerging Directions, Informing Science, 3(2), 89-95 (2000).

33. M. Alvesson and S. Deetz, Doing Critical Management Research, (Sage, London 2000).

34. R. Kling, H. Rosenbaum, and S. Sawyer, Understanding and Communicating Social Informatics: A Framework for Studying and Teaching the Human Contexts of Information and Communication Technologies, (Information Today, Inc, New Jersey, 2005).

35. S. Cohen, Folk Devils and Moral Panics (Routledge, London, 2002).

36. P. Jenkins, Moral Panic: Changing Concepts of the Child Molester in Modern America (Yale University Press, New Haven, 1998).

37. E. Monteiro and $\mathrm{O}$. Hanseth, Social shaping of information infrastructure: on being specific about the technology, in: Information technology and changes in organisational work, edited by W. Orlikowski, G. Walsham, M. Jones and J. DeGross (Chapman \& Hall, London, 1995).

38. M. Horkheimer and T. Adorno, Dialectic of Enlightenment, (Herder, New York, 1972).

39. M. Horkheimer, Traditional and critical theory, in: Critical Theory: Max Horkheimer, (Seabury, New York, 1972).

40. E. Klecun, Competing rationalities: a critical study of telehealth in the UK, in: Handbook of Critical Information Systems Research, edited by D. Howcroft and E. Trauth (Edward Elgar, Cheltenham, 2005).

41. H. Richardson, Consuming passions in the 'global knowledge economy', in: Handbook of Critical Information Systems Research, edited by D. Howcroft and E. Trauth (Edward Elgar, Cheltenham, 2005).

42. B. Doolin, Information technology as disciplinary technology: being critical in interpretive research on information systems, Journal of Information Technology, 13, 301-311 (1998).

43. D. Hughes, The Use of New Communications and Information Technologies for Sexual Exploitation of Women and Children, Hastings Women's Law Journal, 13(1) (2002).

44. B. Chatterjee, Last of the rainmacs? Thinking about pornography in cyberspace, in: Crime and the Internet, edited by D. Wall (Routledge London, 2001).

45. F. Lane, Obscene Profits: the Entrepreneurs of Pornography in the Cyber Age (Routledge, New York, 2001).

46. H. McCulloch, Interpol and Crimes against Children, in: Viewing Child Pornography on the Internet, edited by E. Quayle and M. Taylor (Russell House Publishing, 2005).

47. S. Edwards, Prosecuting 'child pornography', Journal of Social Welfare and Family Law, 22(1), 1-21 (2000).

48. A. Gillespie, The Sexual Offences Act 2003: Tinkering with 'child pornography', Critical Law Review, 361-368 (2004).

49. L. Nilsson, Sexuell exploatering av barn - vad döljer sig bakom sexualbrottsstatistiken? (Brottsförebyggande rådet, Sweden, 2003). 
50. C. Avgerou and K. McGrath, Rationalities and Emotions in IS Innovation, in: Handbook of Critical Information Systems Research, edited by D. Howcroft and E. Trauth (Edward Elgar, Cheltenham, 2005).

51. C. Mackinnon and A. Dworkin, In Harm's Way: The Pornography Civil Rights Hearings, (Harvard University Press, Cambridge Massachusetts, 1997).

52. S. Easton, The Problem of Pornography: Regulation and the Right to Free Speech, (Routledge, London, 1994).

53. L. Edwards, Pornography and the Internet, in: Law \& the Internet: A Framework for Electronic Commerce, edited by L. Edwards and C. Waelde (Hart Publishing, Oxford, 2002).

54. H. Rheingold, The Virtual Community: Homesteading on the Electronic Frontier, (MIT Press, Cambridge Massachusetts, 2000).

55. M. Eneman, A Critical Study of ISPs Filtering of Child Pornography in Proceedings of 14th European Conference on Information Systems, Gothenburg, June 12-14, (2006).

56. M. Smith and P. Kollock, (eds) Communities in Cyberspace, (Routledge, London, 1999).

57. T. Krone, Combating Online Child Pornography in Australia, in: Viewing Child Pornography on the Internet, edited by E. Quayle and M. Taylor (Russell House Publishing, 2005).

58. K. Durkin, Misuse of the Internet by Paedophiles: Implications for Law Enforcement Probation Practice, Federal Probation, 14, (1997).

59. N. Baym, Interpersonal Life Online, in: The Handbook of New Media, edited by L. Lievrouw and S. Livingstone (Sage, London, 2002).

60. S. Livingstone, Children's use of the Internet: reflections on the emerging research agenda, New Media \& Society, 5(2), 147-166 (2003).

61. G. Walsham, Critical engagement: why, what and how?, in: Handbook of Critical Information Systems Research, edited by D. Howcroft and E. Trauth (Edward Elgar, Cheltenham, 2005).

62. A. Feenberg, Transforming Technology: A Critical Theory Revisited (OUP, Oxford, 2002).

63. M. Alvesson and K. Skoldberg, Reflexive Methodology (Sage, London, 1999). 